\title{
An engineered genetic circuit for lactose intolerance alleviation
}

\author{
Mingyue Cheng ${ }^{1,2,3 \dagger} \mathbb{D}$, Zhangyu Cheng ${ }^{1,2 \dagger}$, Yiyan Yu ${ }^{1,2}$, Wangjie Liu ${ }^{1,2}$, Ruihao Li $\mathrm{Li}^{1,2}$, Zhenyi Guo ${ }^{1,2}$, Jiyue Qin ${ }^{1,2}$, \\ Zhi Zeng ${ }^{1,2}$, Lin Di ${ }^{1,2}$, Yufeng Mo ${ }^{1,2}$, Chunxiu Pan ${ }^{1,2}$, Yuanhao Liang ${ }^{1,2}$, Jinman Li ${ }^{4}$, Yigang Tong ${ }^{4,5}$, Yunjun Yan ${ }^{1,3^{*}}$, \\ Yi Zhan ${ }^{1,2,3^{*}}$ and Kang Ning ${ }^{1,3^{*}}$
}

\begin{abstract}
Background: Lactose malabsorption occurs in around $68 \%$ of the world's population, causing lactose intolerance (LI) symptoms, such as abdominal pain, bloating, and diarrhea. To alleviate LI, previous studies have mainly focused on strengthening intestinal $\beta$-galactosidase activity while neglecting the inconspicuous drop in the colon $\mathrm{pH}$ caused by the fermentation of non-hydrolyzed lactose by the gut microbes. A drop in colon pH will reduce the intestinal $\beta$-galactosidase activity and influence intestinal homeostasis.

Results: Here, we synthesized a tri-stable-switch circuit equipped with high $\beta$-galactosidase activity and pH rescue ability. This circuit can switch in functionality between the expression of $\beta$-galactosidase and expression of L-lactate dehydrogenase in response to an intestinal lactose signal and intestinal pH signal, respectively. We confirmed that the circuit functionality was efficient in bacterial cultures at a range of $\mathrm{pH}$ levels, and in preventing a drop in $\mathrm{pH}$ and $\beta$-galactosidase activity after lactose administration to mice. An impact of the circuit on gut microbiota composition was also indicated.

Conclusions: Due to its ability to flexibly adapt to environmental variation, in particular to stabilize colon $\mathrm{pH}$ and maintain $\beta$-galactosidase activity after lactose influx, the tri-stable-switch circuit can serve as a promising prototype for the relief of lactose intolerance.
\end{abstract}

Keywords: Lactose intolerance, Genetic engineering, Synthetic biology, Gut microbiota, In vitro simulation, In vivo assessment

\section{Background}

Lactose malabsorption, defined as the inefficient absorption of lactose, is reported to have a global prevalence of $68 \%$ until 2016 [1]. Symptoms of lactose intolerance (LI), defined as the presence of gastrointestinal symptoms caused by lactose malabsorption within the small intestine, occur when non-hydrolyzed lactose flows into the colon as a substrate for bacteria $[1,2]$. This non-hydrolyzed lactose brings a high

\footnotetext{
* Correspondence: yanyunjun@hust.edu.cn; zhanyi@hust.edu.cn; ningkang@hust.edu.cn

${ }^{\dagger}$ Mingyue Cheng and Zhangyu Cheng contributed equally to this work. ${ }^{1}$ College of Life Science and Technology, Huazhong University of Science and Technology, 430074 Wuhan, People's Republic of China

Full list of author information is available at the end of the article
}

osmotic load into the colon luminal contents, which leads to increased water and electrolytes within the lumen, followed by stool softening, thus causing abdominal pain and cramps [3]. Additionally, lactose can be fermented into lactic acid and other short-chain fatty acids with gaseous products such as hydrogen, methane, and carbon dioxide, thus causing flatulence and diarrhea [3, 4].

The current treatments for LI mainly include dietary control, enzyme replacement therapy, and probiotic supplement. For dietary control, the moderation or restriction of lactose intake is recommended to relieve symptoms [5-7], which impacts people's enjoyment of dairy products. Additionally, a recent study found that the

(c) The Author(s). 2021 Open Access This article is licensed under a Creative Commons Attribution 4.0 International License, which permits use, sharing, adaptation, distribution and reproduction in any medium or format, as long as you give appropriate credit to the original author(s) and the source, provide a link to the Creative Commons licence, and indicate if changes were made. The images or other third party material in this article are included in the article's Creative Commons licence, unless indicated otherwise in a credit line to the material. If material is not included in the article's Creative Commons licence and your intended use is not permitted by statutory regulation or exceeds the permitted use, you will need to obtain permission directly from the copyright holder. To view a copy of this licence, visit http://creativecommons.org/licenses/by/4.0/. The Creative Commons Public Domain Dedication waiver (http://creativecommons.org/publicdomain/zero/1.0/) applies to the data made available in this article, unless otherwise stated in a credit line to the data. 
administration of the highly purified short-chain galactooligosaccharide can help to adjust gut microbiota in order to improve LI [8]. Enzyme replacement therapy is another approach for individuals with LI [9]. Exogenous lactase intake may help lactose digestion and absorption for LI subjects, but its efficacy still lacks convincing evidence [2]. Compared to short-acting enzyme replacement, probiotic supplements have an advantage in their sustainability, [10] and a certain number of studies have confirmed that they can alleviate LI [11-13]. The key function of probiotics is to enhance the intestinal $\beta$-galactosidase ( $\beta$-GAL) activity to aid in lactose digestion in the LI individual. Moreover, the endogenous $\beta$-GAL produced by the probiotics can persist more stably in the intestine. However, conventional bacteria cannot handle the $\mathrm{pH}$ drop caused by the fermentation lactose by the gut microbiota. The $\mathrm{pH}$ drop would cause physical discomfort, such as diarrhea, and most likely reduce the $\beta$-GAL activity $[14,15]$, thereby influencing the intestinal homeostasis.

Genetical engineering, which allows for precise control over a genomic sequence [16], might be the solution for the $\mathrm{pH}$ drop that affects non-modified bacteria. Current designs of engineered bacteria have been confirmed as effective for purposes such as infectious disease treatment [17] and cancer diagnostics [18], via synthetic biology. Moreover, engineered bacteria are believed to work more precisely and efficiently in addressing these diseases [19] as compared to wild-type bacteria. Previously, a recombinant strain expressing food-grade $\beta$-GAL for LI was constructed and evaluated [20, 21]. However, this engineered strain was still unable to handle the $\mathrm{pH}$ drop. As such, a stress-responsive system has the potential to make the bacteria more adaptable to the $\mathrm{pH}$ variation [22]. However, the influences of bacteria administration and $\mathrm{pH}$ drop on the gut microbiota remain unclear. These influences might be understood by observing gut microbiota variations during the lactose intake and bacteria administration phases.

In this study, we initially designed and constructed a tristable-switch circuit in the plasmid pETDuet1-1 that had two functional states, which responded to signals of intestinal lactose and intestinal $\mathrm{pH}$ variation. Second, we transformed the circuit into the strain Escherichia coli BL21 to form the engineered strain BL21: $p$ ETDuet1-1, which was then used to confirm the functionality of the circuit in vitro and in vivo. Lastly, we investigated the variation of the murine gut microbiota and found that administration of the engineered strain BL21: $p$ ETDuet1-1 was able to recover the gut microbiota of the mice affected by excess lactose intake.

\section{Results}

The tri-stable-switch circuit was designed to switch between two functionalities in response to environmental changes

The tri-stable-switch circuit in the plasmid pETDuet1-1 (Fig. 1a) was designed based on a tri-stable switch derived from the bacteriophage lambda [23]. The mutant lactose-inducible promoter placm (Additional file 1: Table S1) and $\mathrm{pH}$-responsive promoter patp2 (Additional file 1: Table S1) were cloned into this plasmid to sense the signals. The key enzymes applied within the system were the products of lacZ ( $\beta$-galactosidase, $\beta$ GAL, Additional file 1: Table S1) and the fusion gene ompA-lldD (L-lactate dehydrogenase, L-LDH, Additional file 1: Table S1). The strain E. coli BL21 was chosen because it has been commonly used for stable expression of nontoxic exogenous proteins. The circuit was then transformed into E. coli BL21 to form the engineered strain BL21: pETDuet1-1. In theory, BL21: pETDuet1-1 was able to dynamically switch between two functional states, which are regulated by a lactose signal and a $\mathrm{pH}$ signal. The theoretical working principle was as follows.

BL21: $p$ ETDuet1-1 accumulated $\beta$-GAL after it colonized the colon (Fig. 1b). The average $\mathrm{pH}$ in the colon has been reported to be 7.0 [24], which, as a signal, maintained continuous $c I$ gene (Additional file 1: Table S1) expression by inducing the patp 2 promoter. The expression of $c I$, which hindered the transcripts of the gene downstream of the $\mathrm{pR}$ promoter (Additional file 1: Table S1), suppressed expression of ompA-lldD gene and cIII gene (Additional file 1: Table S1), thus ceasing the function of the $\mathrm{pH}$ rescue. At this moment, the engineered bacteria would focus on the expression of the lac $Z$ and accumulate $\beta$-GAL for supplementary lactose digestion when unabsorbed lactose fluxed into the colon.

BL21: $p$ ETDuet1-1 gradually switched from lacZ expression to ompA-lldD expression after lactose fluxed into the colon (Fig. 1c). On the one hand, the lactose, as a signal, triggered the placm promoter, thus activating the positive feedback loop of pRE promoter, cro gene, and $c I I$ gene (Additional file 1: Table S1). The expression of $c r o$ then began to suppress $l a c Z$ expression after $\mathrm{pRM}$ promoter (Additional file 1: Table S1) via binding to its binding site [25]. Additionally, cro expression has been shown to be strengthened by $c I I$ expression, which is inhibited to a degree because $c I I$ expression is still suppressed by endogenous Ftsh gene expression [26]. On the other hand, fermentation of lactose by the gut microbiota has been demonstrated to produce lactic acid and other short-chain fatty acids, leading to a $\mathrm{pH}$ drop within the colon, which would weaken patp 2 and inhibit $c I$ expression. However, previously expressed products of $c I$ would continue to suppress the expression of ompA$I l d D$ and $c I I I$ to a certain degree, and the suppression would gradually diminish as these products are degraded. Hence, ompA-lldD expression would gradually recover to a normal condition, producing a signal peptide [27], and L-LDH [28, 29] would be translocated to the cell membrane to convert lactic acid to pyruvate in the periplasm. Additionally, the gradual recovery of $c I I I$ 

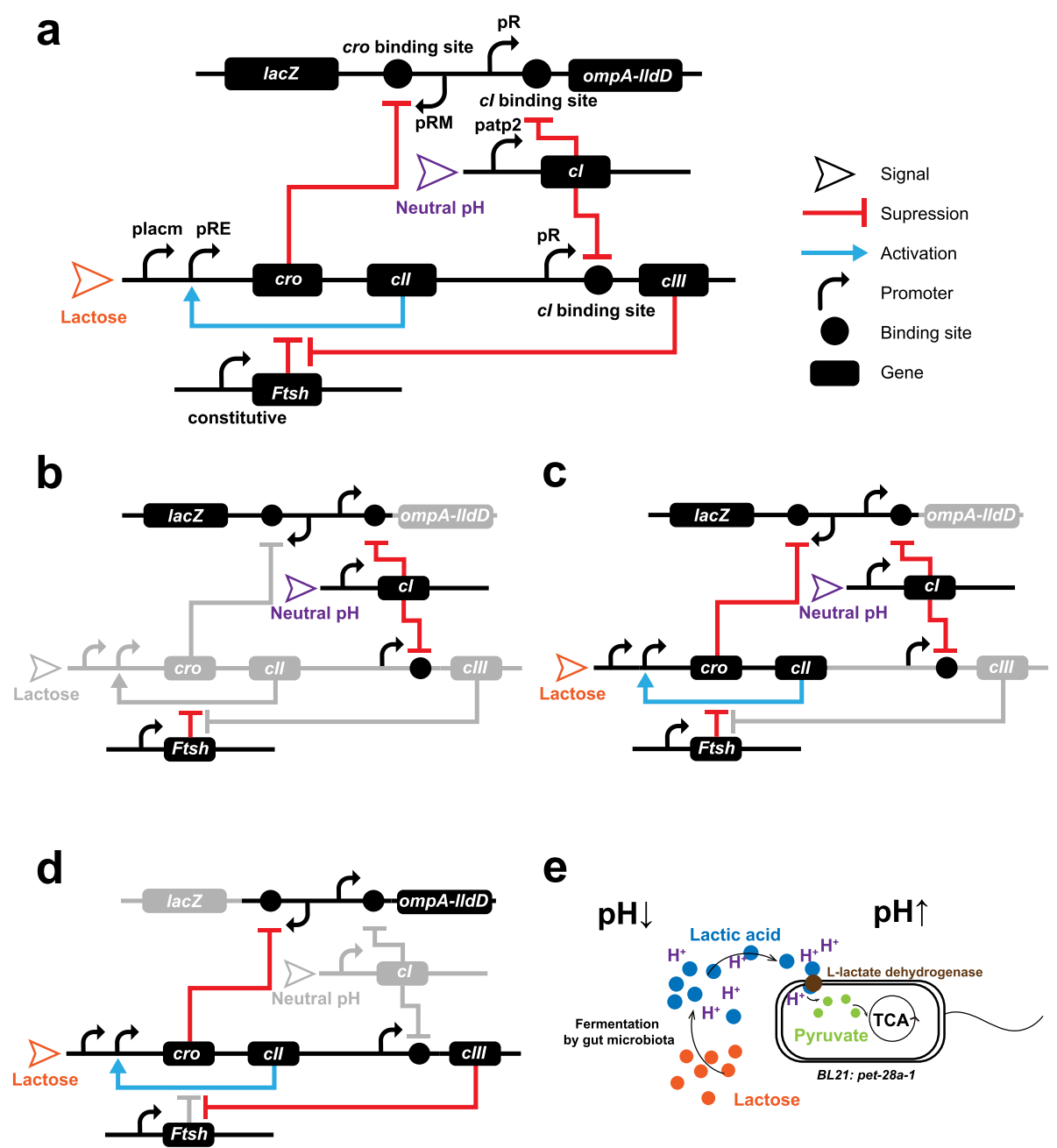

e

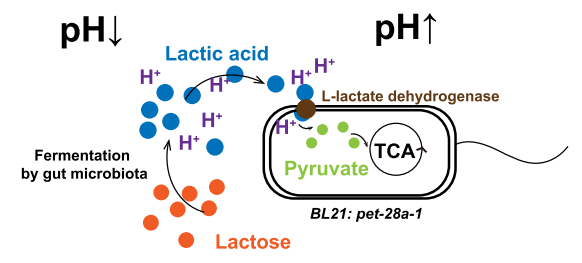

Fig. 1 The tri-stable-switch circuit can switch between two functionalities in response to environmental change. a The design diagram of the tristable switch circuit. Parts of the circuit are derived from the bacteriophage lambda. The two promoters, placm and patp2, were selected to respond to the lactose and $\mathrm{pH}$ signals, respectively. The placm promoter is triggered by lactose, and the patp2 promoter is weakened by the $\mathrm{pH}$ drop. b When BL21: pETDuet1-1 colonizes the colon with a neutral pH, lac $Z$ is stably expressed, and $\beta$-galactosidase ( $\beta$-GAL) accumulates intracellularly. $\mathbf{c}$ When a flux of unabsorbed lactose occurs in the colon, the system switches to a transition state in response to lactose and $\mathrm{pH}$ signals. The expression of ompA-IIdD for L-lactate dehydrogenase (L-LDH) is strengthened, and the expression of lac $Z$ is weakened. $\mathbf{d}$ The system then focuses on the expression of ompA-IIdD. e The fermentation of lactose by the gut microbiota causes a pH drop, while expression of L-LDH transforms lactic acid into pyruvate, thus recovering the $\mathrm{pH}$. The pyruvate then permeates into the cell for the tricarboxylic acid (TCA) cycle

expression would unsuppress $c I I$ expression by inhibiting endogenous expression of Ftsh [26]. Unsuppressed cII expression would then strengthen cro expression, thus accelerating the inhibition of lacZ expression. Once lactose fluxed into the colon, the entire system was in an intermediate state of double functions.

Once the switch process was completed, the BL21: $p E T$ Duet1-1 focused on ompA-lldD expression (Fig. 1d), and the suppression of $c I I I$ and ompA-lldD expression was removed. Constitutive expression of $c I I I$ eliminated the suppression on cII expression via the endogenous expression of Ftsh, thus allowing the lactose-activated positive feedback loop to inhibit the lacZ expression. Expression of ompA-lldD continued to produce efficient signal peptides, allowing L-LDH to convert lactic acid to pyruvate in order to rescue the $\mathrm{pH}$ drop (Fig. 1e). Afterward, the pyruvate would be transported into the cell by its carrier protein $[30,31]$ for usage in the tricarboxylic acid (TCA) cycle [32]. Once the engineered bacteria complete digesting the lactose and restoring the $\mathrm{pH}$, BL21: $p$ ETDuet1-1 would subsequently switch to $\beta$-GAL accumulation until the next round of lactose ingestion. Thus, in this manner, BL21: pETDuet1-1 would alternate its function in response to the lactose intake.

The tri-stable-switch circuit was efficient under a range of $\mathrm{pH}$ conditions in vitro

The interactions between $c I I$ \& pRE, $c I$ \& pR, cro \& $\mathrm{pRM}$, and $c I I I \&$ cII have been tested using fluorescence 
detection (Additional file 1: Table S2, Additional file 1: Table S3, Additional file 2). The circuit switch was also confirmed to work in theory using mathematical simulation (Additional file 1: Table S4, Additional file 2). In order to test the circuit in vitro (Fig. 2), we prepared mediums with three $\mathrm{pH}$ values. In order to simulate the acidic conditions caused by excess lactose intake in the human colon, which typically has a $\mathrm{pH}$ of 7 [24], and the mouse colon, which normally has a $\mathrm{pH}$ of 5 [33], we adjusted the $\mathrm{pH}$ of these mediums by adding $0.1 \%$ lactic acid or $1 \%$ lactose. The three $\mathrm{pH}$ sets included $\mathrm{pH}$ set I (initial $\mathrm{pH}=4.54 \pm 0.012$ ), $\mathrm{pH}$ set II (initial $\mathrm{pH}=5.34 \pm$ 0.02 ), and pH set III (initial pH $=6.25 \pm 0.02$ ).

We subsequently cultured various bacterial strains, including the test strain (BL21: pETDuet1-1, Additional file 3) and the control strain (BL21: pETDuet1-0) with an empty vector (Additional file 4) for $12 \mathrm{~h}$ in these three mediums and recorded the variation in the $\mathrm{pH}$ values and the expressed enzyme activity (Additional file 1: Table S5). As shown in Fig. 2a, the pH values of the control culture and the test culture began to increase at $6 \mathrm{~h}$ post-inoculation. The increase in the $\mathrm{pH}$ within the control culture was associated with two processes: (1) the metabolism of the substantial increase in the bacterial population, and (2) the consumption of the medium. However, the change in $\mathrm{pH}$ within the test culture was also dependent on a third process-expression of L-LDH, which helped facilitate the digestion of lactose and the $\mathrm{pH}$ increase. The increased $\mathrm{pH}$ caused by L$\mathrm{LDH}$ was evident in $\mathrm{pH}$ set $\mathrm{I}$. The $\mathrm{pH}$ of the test culture increased to a higher degree than that of the control culture (test culture: $4.54 \pm 0.02$ to $5.31 \pm 0.075$; control culture: $4.54 \pm 0.01$ to $4.9 \pm 0.072$ ). The $\mathrm{pH}$ increase in the test culture was also observed in $\mathrm{pH}$ sets II and III, but it was not as obvious as that in $\mathrm{pH}$ set I.

As shown in Fig. $2 b$ and $c$, both the $\beta$-GAL activity and L-LDH activity, which were caused by the expression of the lacZ gene and ompA-lldD genes, respectively, in the circuit of BL21: pETDuet1-1, were higher in the test group as compared to the control group. Before $4 \mathrm{~h}$, the enzyme activity measurements were unavailable because of the minimal amount of bacteria. After culturing for $4 \mathrm{~h}$, the $\beta$-GAL activity of the test group continued to steadily increase in all three $\mathrm{pH}$ sets. In addition, 8$10 \mathrm{~h}$ post-inoculation, the $\beta$-GAL activity of the test group increased to the greatest extent and later flattened in $\mathrm{pH}$ sets II and III. Additionally, the L-LDH activity of the test group began to decrease in $\mathrm{pH}$ set II and $\mathrm{pH}$ set
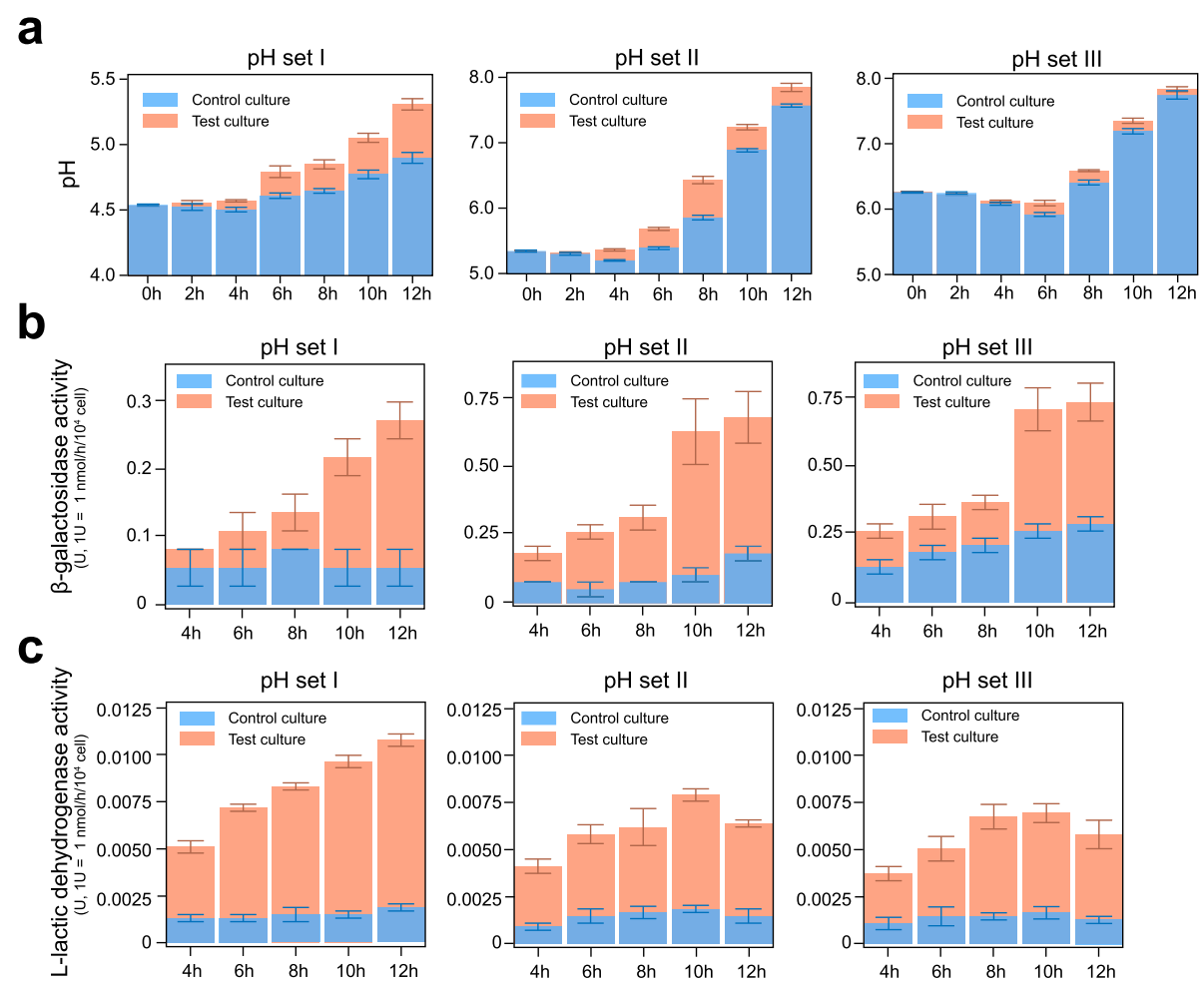

Fig. 2 The tri-stable-switch circuit was efficient under a range of $\mathrm{pH}$ values in vitro. a The $\mathrm{pH}$ variation (mean \pm S.E.M.) that occurred within bacterial cultures during $12 \mathrm{~h}$ of growth under different initial $\mathrm{pH}$ conditions. b The $\beta$-galactosidase ( $\beta$-GAL) activity (mean \pm S.E.M.) that occurred within bacterial cultures grown for $12 \mathrm{~h}$ under different initial $\mathrm{pH}$ conditions. c The L-lactate dehydrogenase (L-LDH) activity (mean \pm S.E.M.) within bacterial cultures that were grown for $12 \mathrm{~h}$ under different initial $\mathrm{pH}$ conditions. In all panels, the control culture (BL21: $p E$ TDuet 1-0) is colored in orange, while the test culture (BL21: pETDuet1-1) is colored in blue. All of the data were produced using three parallel experiments 
III $10 \mathrm{~h}$ post-inoculation. The corresponding $\mathrm{pH}$ range of the test group $8-10 \mathrm{~h}$ post-inoculation was $6.43 \pm$ 0.10 to $7.23 \pm 0.07$ in $\mathrm{pH}$ set II and $6.58 \pm 0.03$ to $7.34 \pm$ 0.07 in $\mathrm{pH}$ set III, which indicated that the dual-function switch of the circuit was completed for these $\mathrm{pH}$ ranges. These results suggested that relatively low $\mathrm{pH}$ values promote L-LDH expression in the circuit in order to remove the lactic acid to prevent the increase in $\mathrm{pH}$. The increased $\mathrm{pH}$ then makes the circuit begin to switch gradually from L-LDH expression to $\beta$-GAL expression, which would continue until the $\mathrm{pH}$ is close to neutral.

\section{The tri-stable-switch circuit helped mice to recover the $\mathrm{pH}$ drop caused by excess lactose intake}

The in vitro experiments confirmed the theoretical feasibility of the tri-stable-switch circuit to alleviate LI by switching between $\beta$-GAL expression and L-LDH expression, but whether it could work in vivo remained unclear. We thus divided 84 mice into five groups, including (1) initial set $(\mathrm{n}=4),(2)$ untreated group ( $\mathrm{n}=$ $20)$, (3) model group $(\mathrm{n}=20)$, (4) control group ( $\mathrm{n}=$ $20)$, and (5) test group $(\mathrm{n}=20)$ in order to investigate how the circuit functioned in vivo. As shown in Fig. 3a, mice in the control and test groups were administrated bacteria (BL21: pETDuet1-O in the control group and BL21: $p$ ETDuet1-1 in the test group; $\mathrm{OD}_{600}=1$ ) in a total volume of $0.3 \mathrm{~mL}$ in a $0.9 \%$ NS suspension daily during the first week. The bacteria were confirmed to colonize the colons of the mice, which lasted for at least $24 \mathrm{~h}$ (Additional file 2). The other groups were given the same volume of normal saline (NS) daily. The $\mathrm{pH}$ of the colons of the mice in the initial set was set as the $\mathrm{pH}$ value at $0 \mathrm{~h}$ for all groups. At the time point of $0 \mathrm{~h}$, mice of the model, control, and test groups were administrated the lactose solution (12 $\mathrm{mg}$ of lactose per $20 \mathrm{~g}$ of body weight), and mice of the untreated group were administrated the same volume of $0.9 \% \mathrm{NS}$. The $\mathrm{pH}$ values of the colons of the mice in the remaining four groups were then tested at each time point (Additional file 1: Table S6) and graphed to illustrate the variation in $\mathrm{pH}$ (Fig. 3b). The colon $\mathrm{pH}$ of the model group and control group decreased to $4.66 \pm 0.15$ and $4.72 \pm 0.25$, respectively, from $0 \mathrm{~h}$ to $3 \mathrm{~h}$, and then recovered to $4.89 \pm 0.24$ and $4.94 \pm 0.1$, respectively, from $3 \mathrm{~h}$ to $6 \mathrm{~h}$. However, the colon $\mathrm{pH}$ value of the untreated group without lactose intake and the colon $\mathrm{pH}$ of the test group with BL21: $p$ ETDuet1-1 were relatively stable. Thus, these results indicated that the tri-stable-switch circuit prevents the $\mathrm{pH}$ drop in mouse colons caused by an excessive intake of lactose, thereby restoring intestinal homeostasis and relieving LI.

Moreover, we then tested fecal $\beta$-GAL activity using another set of the four groups of mice, including (1) untreated group $(\mathrm{n}=3)$, (2) model group $(\mathrm{n}=3)$, (3) control group $(n=3)$, and (4) test group $(n=3)$. The operations in the first week and at the time point of $0 \mathrm{~h}$ were the same as the operations described above (Fig. $3 c)$. We then tested the $\beta$-GAL activity in the feces of mice before the time point of $0 \mathrm{~h}$, and at the time point of $3 \mathrm{~h}$ (Additional file 1: Table S7, Fig. 3d). The $\beta$-GAL activity of the test group was found kept at a high and stable level $(P=0.27$, Student's $t$ test), suggesting that the colonization of the BL21: pETDuet1-1 has prepared enough $\beta$-GAL activity for the following lactose intake. No evident variation in the $\beta$-GAL activity of the untreated group was observed as well $(P=0.68$, Student's $t$ test). Nevertheless, the $\beta$-GAL activity of the model and control groups significantly decreased at $3 \mathrm{~h}$ (model group: $P=0.0072$, control group: $P=0.0015$, Student's $t$ test). These results indicated that the colon $\mathrm{pH}$ drop might decrease the intestinal $\beta$-GAL activity, and the tristable-switch circuit could keep intestinal $\mathrm{pH}$ stability and high intestinal $\beta$-GAL activity.

\section{The tri-stable-switch circuit helped the murine gut microbiota recover from the effects of excessive lactose intake}

In order to understand the effects of the engineered bacteria on the murine gut microbiota, we conducted a time-series experiment using a high-frequency sampling of mice fecal samples (Additional file 1: Table S8). As shown in Fig. 4a, four groups of mice (i.e., untreated group, model group, control group, and test group) were subjected to different interventions. The experiment lasted for 21 days and was divided into the four phases: normal care (Phase I), lactose challenge (Phase II), bacterial treatment (Phase III), and restoration (Phase IV). For Phase I, during which the four groups received normal care, the objective was to stabilize the physical signs and the gut microbiota of the mice in the four groups. For Phase II, during which lactose was fed to the model, control, and test groups, the objective was to investigate the influence of excess lactose on the gut microbiota. Phase III, in which BL21: $p$ ETDuet1-1 was fed to the test group while empty-vector-containing BL21: $p$ ETDuet1-0 was fed to mice in the control group, was used to determine whether BL21: pETDuet1-1 can alleviate LI. In Phase IV, we intended to observe whether the bacteria caused any side effects in the host mice.

The dynamics of the mice gut microbiota differed among the four groups over the 21-day trial. From days 3 to 11 , most of the gut microbiota samples from the Untreated group trended toward the right end of the principle coordinate 1 ( $\mathrm{PCo} 1$ ) axis, whose degree was more considerable than those of the mouse groups administrated with lactose (Fig. 4b, c). In other words, excessive lactose intake inhibited the shift in the microbiota toward the right end of the $\mathrm{PCo} 1$ axis during 

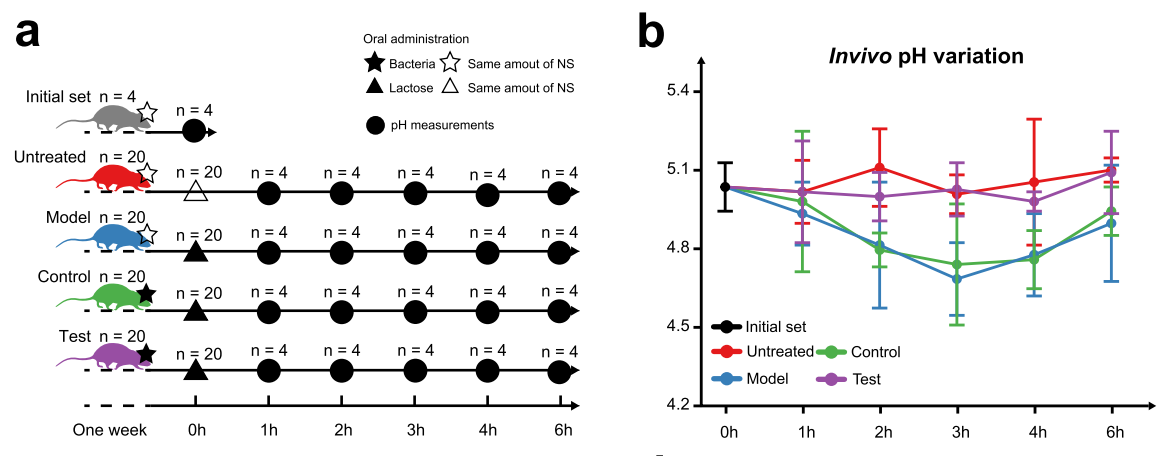

C

d
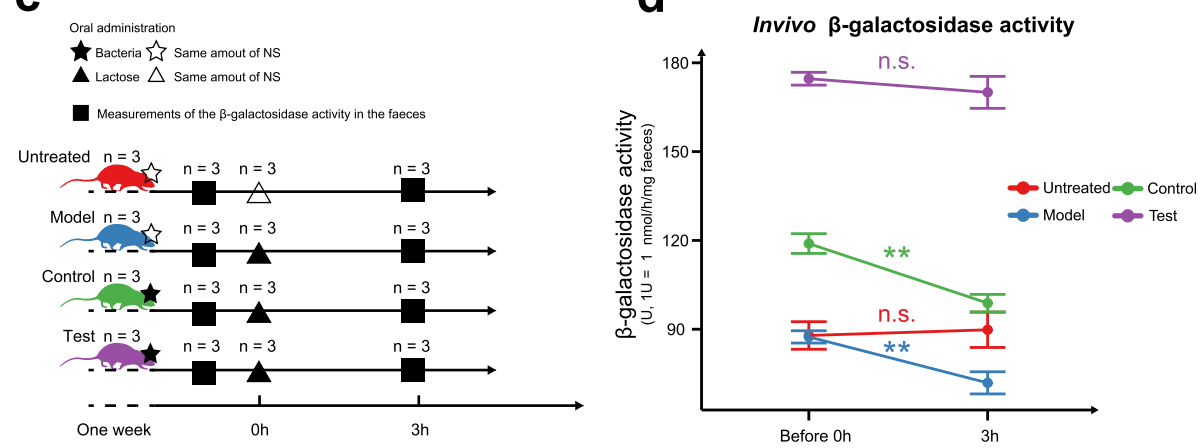

Fig. 3 The tri-stable-switch circuit helped mice recover from the $\mathrm{pH}$ drop caused by excess lactose intake. a Five groups of mice: (1) initial set ( $\mathrm{n}$ $=4)$, (2) untreated group $(n=20)$, (3) model group $(n=20)$, (4) control group $(n=20)$, and (5) test group $(n=20)$ were subjected to different operations in the first week. Mice in the control group and the test group were administrated with bacteria (BL21: pETDuet 1-0 in the Control group, BL21: pETDuet1-1 in the test group; $\mathrm{OD}_{600}=1$ ) in a total volume of $0.3 \mathrm{~mL}$ of a $0.9 \%$ normal saline (NS) suspension daily. The other groups were administrated daily with the same volume of $0.9 \% \mathrm{NS}$. At the time point of $0 \mathrm{~h}$, mice in the initial set were euthanized for $\mathrm{pH}$ measurements. The mice of the model, control, and test group were administrated the lactose solution ( $12 \mathrm{mg}$ of lactose per $20 \mathrm{~g}$ of body weight), and the mice of the untreated group were administrated the same volume of $0.9 \%$ NS. During the following $6 \mathrm{~h}$, four mice from each group were euthanized at each time point for $\mathrm{pH}$ measurements. b The $\mathrm{pH}$ variation (mean \pm S.D.) of the mouse colons during $6 \mathrm{~h}$. The initial set is designated as the initial point of four other groups. The $\mathrm{pH}$ variation of different groups is colored differently. The $\mathrm{pH}$ variation of the model and control group is statistically significant $(P<0.05$, Student's $t$ test, Additional file 1: Table S6). c Four groups of mice: (1) untreated group $(n=$ 20), (2) model group $(n=20)$, (3) control group $(n=20)$, and (4) test group $(n=20)$ were subjected to different operations in the first week, as described in $\mathbf{a}$. Before the time point of $0 \mathrm{~h}$, mice of all the groups were stimulated to defecate for measurements of $\beta$-galactosidase activity. At the time point of $0 \mathrm{~h}$, mice of the model, control, and test group were administrated the lactose solution ( $12 \mathrm{mg}$ of lactose per $20 \mathrm{~g}$ of body weight), and mice of the untreated group were administrated the same volume of $0.9 \%$ NS. At the time point of $3 \mathrm{~h}$, mice of all the groups were stimulated to defecate for measurements of $\beta$-galactosidase activity. $\mathbf{d}$ The $\beta$-galactosidase activity variation (mean \pm S.D.) of the mouse feces during $6 \mathrm{~h}$. The variation of different groups is colored differently. ${ }^{*} \mathrm{P}<0.05$, ${ }^{* *} \mathrm{P}<0.01$; n.s., not significant. Student's $t$ test

this period, which began to be obvious at day 7. Nevertheless, among lactose-affected gut microbiotas, only those of the test group arrived at the same degree as those of the untreated group (Figs. 4b, c) after a time lag. Thus, it appeared as though the engineered bacteria were able to weaken some restrictive effects of the lactose.

We then constructed an unweighted-glasso network based on amplicon sequence variants (ASVs). To figure out the exact taxa affected by the inhibitory effects, we calculated the mean abundances of the top 50 most abundant ASVs in the network using samples from three data subsets including "normal condition," "lactose feeding," and "treatment" (Fig. 4d, Additional file 1: Table S8). We used samples of the untreated group at days 7 and 11 for the network of "normal condition" because they were most prominent characteristics in the normal stage (Fig. 4c). We used the samples from the model and control at days 5, 7, and 11 and test groups at days 5 and 7 for the network of "lactose feeding" because these samples were under the effects of lactose. We used the samples from the test group at days 11 and 13 for network of "treatment" because these samples have been treated with engineered bacteria. The networks showed that the microbial patterns would be largely affected by lactose intake and then recovered to the pattern that was similar to the original normal pattern after bacterial treatment (Fig. 4d).

Moreover, we found that 35 out of 50 most abundant ASVs in the networks were classified as class Bacteroidia (Additional file 1: Table S9), and genus Bacteroides was the most common genus in the altered microbiota and 


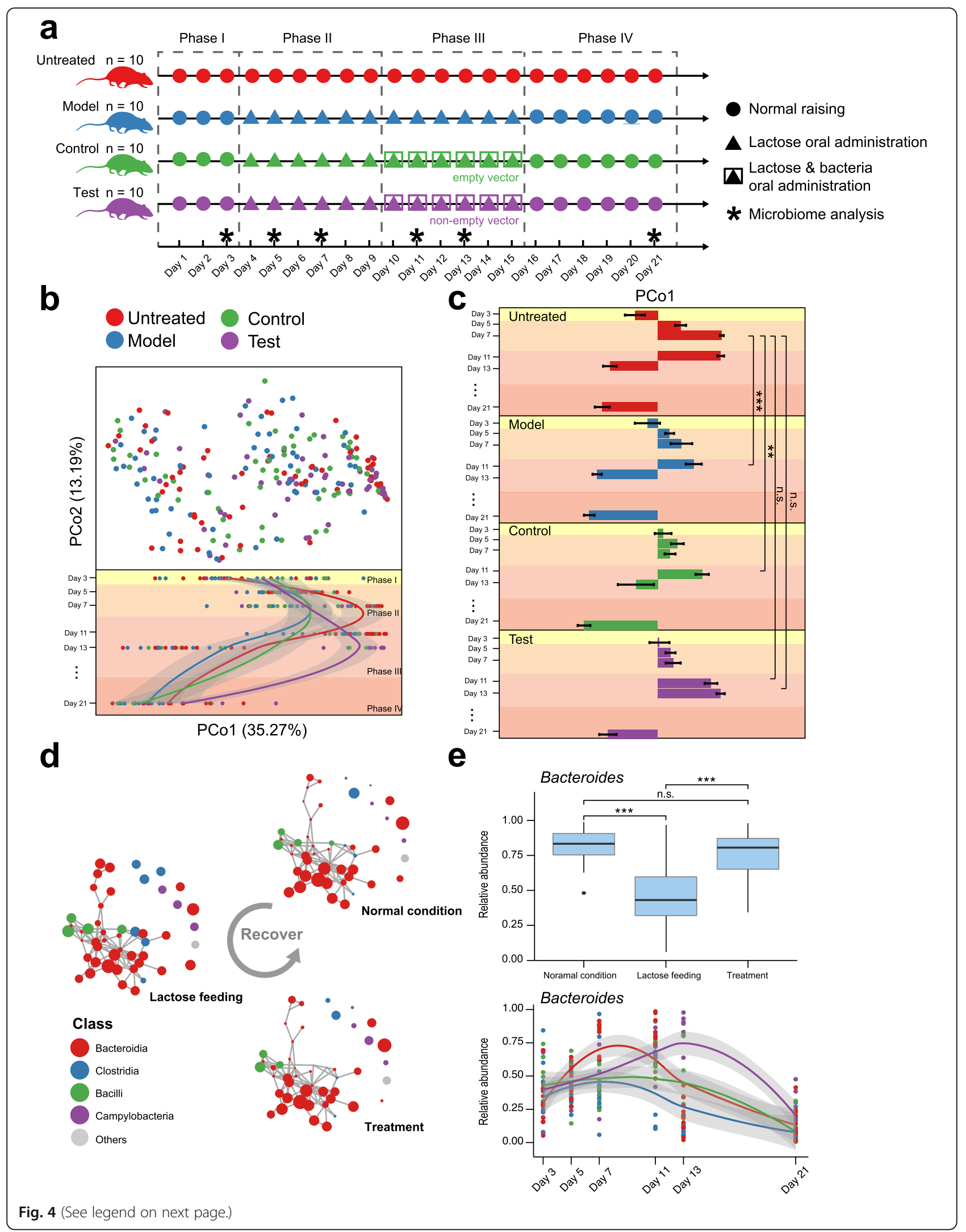




\section{(See figure on previous page.)}

Fig. 4 The tri-stable-switch circuit helped the gut microbiota of mice recover from the effects of excess lactose intake. a The design of the murine experiment for gut microbiota profiling. b Top panel: The gut microbiota composition of individual mice in the untreated group ( $n=58$ ), model group ( $n=59)$, control group $(n=53)$, and test group $(n=55)$ plotted on a principal coordinate analysis (PCoA) using Jensen-Shannon Divergence (JSD). Bottom panel: The gut microbiota samples are plotted according to their collection date on the $y$-axis over 21 days, and their position on the $x$-axis is plotted according to their first principal coordinate in the JSD PCoA. A Loess regression is applied to these points using the collection date and principal coordinate 1 (PCo1) coordinates, and the curves are plotted in different colors according to their groups, with the $95 \%$ pointwise confidence interval band shaded gray. c The PCo1 coordinates (mean \pm S.E.M.) from the four trial groups across 21 days. ${ }^{*} \mathrm{P}<$ 0.05 , ** $P<0.01$, ${ }^{* *} P<0.001$; n.S., not significant. Mann-Whitney-Wilcoxon test. $\mathbf{d}$ The network was constructed using unweighted adjacency matrices produced by SPIEC-EASI. Sparse inverse covariance estimation based on glasso determined whether there was a correlation in abundance between the two amplicon sequence variants (ASVs), indicated by the gray edge. The size of the node represents the mean abundance calculated using different subsets of samples (defined in the "Results" section and "Methods" section). The color of the node represents the class level that the ASV is classified as. e Top panel: The boxplot displays the differences in Bacteroides abundance among the three data subsets in $\mathbf{d}$. ${ }^{* *} \mathrm{P}<0.001$; n.S., not significant. Mann-Whitney-Wilcoxon test. Bottom panel: Each of the points represents the Bacteroides abundance of one sample from the four groups defined in $\mathbf{a}$. A Loess regression was applied to these points, and the curves are plotted in different colors according to their groups, with the $95 \%$ pointwise confidence interval band shaded gray

whose altered abundance was highly accordant with the microbiota variation against PCo1 (Fig. 4c, e). As compared to the "normal condition" network, 29 out of 50 most abundant ASVs were differentially abundant in the "lactose feeding" network, but had an abundance similar to the "treatment" network. For instance, an ASV that is most likely Bacteroides acidifaciens (confidence: 0.90) had an abundance of $0.285 \pm 0.036$ in the "normal condition" network and a similar abundance of $0.282 \pm$ 0.037 in the "treatment" network, but it had a decreased abundance of $0.199 \pm 0.016$ in the "lactose feeding" network ( $P=0.027$, Wilcox test). Other ASVs that were also most likely Bacteroides acidifaciens were found to have similar distributions (Additional file 1: Table S9). Additionally, an ASV that is most likely Lactobacillus murinus (confidence 0.92) had increased abundance in the "lactose feeding" network as compared to that in "normal condition" network $(P=0.001$, Wilcox test), while there was no significant difference in its abundance found between the "normal condition" network and the "treatment" network. These results indicated that excessive intake of lactose might inhibit the growth of the genus Bacteroides in the gut microbiota of mice during Phase II, while the administration of BL21: $p E T$ Duet1-1 removed this inhibition, such that the murine gut microbiota proceeded to the variation in Phase III, similar to the gut microbiota of the untreated mice in Phase II.

\section{Discussion}

In this study, we designed a tri-stable-switch circuit with the ability of $\beta$-GAL accumulation and $\mathrm{pH}$ rescue. The engineered bacteria equipped with this circuit can flexibly adapt to the variation of the intestinal environment, thus timely digesting lactose and rescuing the intestinal $\mathrm{pH}$ drop, along restoring the gut microbiota. We believe using engineered bacteria equipped with this tri-stableswitch circuit can serve as a promising method for LI.
The tri-stable-switch circuit compensates for the defect of non-modified bacteria by digesting lactose and enabling an additional function of $\mathrm{pH}$ rescue. The $\mathrm{pH}$ drop caused by the fermentation of lactose by the gut microbiota causes diarrhea and reduces the activity of the intestinal $\beta$-GAL and disrupts intestinal homeostasis. Therefore, the tri-stable-switch circuit was designed to respond to the signals of $\mathrm{pH}$ and lactose concentration and then dynamically switch between two functional states: accumulation of $\beta$-GAL and $\mathrm{pH}$ rescue. The accumulation of $\beta$-GAL facilitates the digestion of lactose with high efficiency, while the $\mathrm{pH}$ rescue function maintains intestinal homeostasis, thereby giving the bacteria engineered with this circuit better adaptability to the intestinal environment than non-modified bacteria. These two functions have been confirmed in our in vitro and in vivo assays.

Interestingly, in a 21-day in vivo mouse experiment, the engineered bacteria with the tri-stable-switch circuit might recover the murine gut microbiota from the effects of excessive lactose intake. Once lactose flowed into the colon, the fermentation of the unabsorbed lactose by the native gut microbiota would produce acids and gas, which resulted in a $\mathrm{pH}$ drop in the colon. This environmental change within the colon would, in turn, influence the native gut microbiota. However, colonization of the engineered bacteria would influence the native microbiota through microbial interactions, and the expression of $\beta$-GAL and L-LDH would also influence the intestinal environment. We found that the normal variation within the intestinal microbiota was affected by the excessive intake of lactose and found the lactose effects were eliminated to a certain degree by the engineered bacteria. The microbe most influenced by this process was Bacteroides acidifaciens, whose growth was previously reported to prevent obesity and improve insulin sensitivity in mice [34]. This study provides a reservoir of the influenced microbes, further investigations on which are warranted in future. 
This study has limitations. First, this study mainly underscores the design of the tri-stable-switch circuit and the confirmation of its functionality. Hence, for this purpose, the E. coli BL21 strain would be more suitable for confirmation of the functionality of a prototype rather than for therapeutic intention. To apply this tri-stableswitch circuit to humans still needs more sophisticated studies in order to determine a proper chassis and ensure safety. Second, it is already known that the $\mathrm{pH}$ of the mice colon is lower than that of the human colon. The switch of the tri-stable-switch circuit was engineered to complete its functions in a $\mathrm{pH}$ range close to a neutral condition, which better fits in the human intestine. Nevertheless, we observed in the in vitro experiments using a broad range of $\mathrm{pH}$ conditions, the tristable-switch circuit still works well at a lower $\mathrm{pH}$. Third, it was a missed chance for us to investigate on the variation of the absolute bacterial amount, which might help to characterize the lactose induced dysbiosis. Forth, we are not able to explain why the gut microbiota of mice in the untreated group was unstable. However, we have shown that the microbiota can be affected by an excessive intake of lactose and restored via administration of bacteria engineered with the tri-stable-switch circuit.

\section{Conclusions}

In summary, the tri-stable-switch circuit can serve as a promising prototype for LI symptoms relief, especially by flexibly adapting to environmental variation, stabilizing colon $\mathrm{pH}$, and maintaining $\beta$-galactosidase activity after lactose influx.

\section{Methods}

\section{Experimental design}

This study aimed to construct a genetic circuit with a tri-stable switch. To test the functionality of the circuit, we used a $12-\mathrm{h}$ in vitro simulation and a 6 -h in vivo experiment to verify that the circuit works in lactose digestion and $\mathrm{pH}$ adjustment. We also used a 21-day in vivo model to monitor the variation of the murine gut microbiota under the influence of the circuit.

\section{Circuit construction}

Sequences were synthesized by Integrated DNA Technologies (IDT, Coralville, IA, USA) as PCR templates. The 3A assembly was based on isocaudomer digestion and ligation. Forward primers included prefix $5^{\prime}$-GAAT TCGCGGCCGCTTCTAG-3' for the coding sequence and 5'-GAATTCGCGGCCGCTTCTAGAG-3' for the non-coding sequence. Reverse primers contained the suffix 5'-TACTAGTAGCGGCCGCTGCAG-3'. Then the prefix and suffix were added to the DNA segments through PCR (Additional file 5: Table S10). The double enzyme reaction was then performed on these DNA products (Additional file 5: Table S11). The pSB1C3 backbone and target DNA segments with sticky ends were assembled together by T4 ligase (Additional file 5: Table S12). In-Fusion was then used to assemble the functional circuits with the 3A-assembled intermediate parts. The $5^{\prime}$ end of the In-Fusion primer contained 15 bases that were homologous to 15 bases at the end of the DNA fragment it joined. The system was incubated (Additional file 5: Table S13) for $15 \mathrm{~min}$ at $50{ }^{\circ} \mathrm{C}$, and it was then placed on ice.

\section{Transformation}

All cloning plasmids (with the $p B C 1 C 3$ backbone) were transformed into $E$. coli $D H 5 \alpha$ cells by the standard competent cell transformation method [35]. The strains were cultivated on Luria-Bertani (LB) plates (1\% tryptone, $0.5 \%$ yeast extract, $1 \% \mathrm{NaCl}$, and $1 \%$ agar) at $37^{\circ} \mathrm{C}$. For positive selection, ampicillin (1\%) was applied to the medium. The complete parts were cloned into the $p E T$ Duet-1 backbone by inserting it into the PstI site. The extracted plasmids (with the pETDuet-1 backbone containing the $\mathrm{T} 7$ promoter conserved in E. coli $D H 5 \alpha$, Additional file 3) were transformed into E. coli BL21 for gene expression. E. coli BL21 encodes a native $\beta$ galactosidase, but does not encode a native L-lactate dehydrogenase. Thus, E. coli BL21, which was transformed with an empty plasmid ( $p$ ETDuet-0, Additional file 4), was used as a control for the other experiments.

\section{Fluorescence detection}

First, $0.2 \%$ (volume) of activated bacteria containing constructed circuit and their respective control was inoculated into M9 medium (Additional file 5: Table S14) and cultured overnight in a $37^{\circ} \mathrm{C}$ shake incubator. Bacteria without the pathways were set as a blank control. Then $10 \%$ (volume) of the bacterial culture was inoculated into fresh medium and cultured to an OD600 of 0.6. The bacterial culture was then diluted with the corresponding medium to an OD600 of 0.1 , and isopropyl $\beta$ D-thiogalactopyranoside (IPTG) $(1 \mathrm{mg} / \mathrm{mL})$ was added into the culture. The culture was incubated continuously at $37^{\circ} \mathrm{C}$ in the dark. Every hour, a $100-\mu \mathrm{L}$ aliquot of the culture for each sample was added into a black 96-well plate to measure both the fluorescence and $\mathrm{OD}_{600}$ (Additional file 5: Table S15). Before measurement, the plate was covered with tin foil.

\section{2-h in vitro simulation}

The Luria-Bertani (LB) broth medium was firstly made and sterilized. The $0.1 \%$ sterilized lactic acid and $1 \%$ sterilized lactose were then added to the LB medium. The adding of lactic acid and lactose was used to simulate the case that the excessive lactose flowed into the 
colon, part of which was then fermented to lactic acid by gut microbiota. To simulate the environmental $\mathrm{pH}$ of the mice colon and human colon, we used $1 \mathrm{M}$ sterilized $\mathrm{NaOH}$ and $1 \mathrm{M}$ sterilized $\mathrm{HCl}$ to adjust the $\mathrm{pH}$ values of the LB mediums to three $\mathrm{pH}$ sets, including the $\mathrm{pH}$ set I (initial $\mathrm{pH}=4.54 \pm 0.012$ ), the $\mathrm{pH}$ set II (initial $\mathrm{pH}=$ $5.34 \pm 0.02$ ), and the $\mathrm{pH}$ set III (initial $\mathrm{pH}=6.25 \pm$ $0.02)$. Then, $1 \%$ ampicillin was added to eliminate contamination. The control strain BL21: $p$ ETDuet1-O and the test strain BL21: pETDuet1-1 were then inoculated into the three $\mathrm{pH}$ sets with three replicates at initial $\mathrm{OD}_{600}$ of 2.038 and 2.081. During the $12 \mathrm{~h}$ in vitro culturing, $2 \mathrm{ml}$ of the culture was taken out every $2 \mathrm{~h}$ at the clean bench to measure the $\mathrm{pH}$ value and the enzyme activity. The $\beta$-galactosidase activity was determined by the colour reaction of p-nitrophenol using " $\beta$-galactosidase activity test kit" (Solarbio, Cat. No. BC2585, Beijing, China). The l-lactate dehydrogenase activity was determined by pyruvate's colour reaction using "l-lactate dehydrogenase (L-LDH) activity test kit" (Solarbio, Cat. No BC0685, Beijing, China).

\section{6-h in vivo experiment}

The 6-h in vivo experiment was conducted on postweaning $\mathrm{BALB} / \mathrm{c}$ mice, which was demonstrated and used as the LI model mice in previous studies [20]. Male $\mathrm{BALB} / \mathrm{c}$ mice from animal care aged 7 8 weeks were used for the trial. Before the test, mice were housed under specific pathogen-free (SPF) conditions with a 12h light/dark cycle (8 AM-8 PM for light, 8 PM-8 AM next day for dark) and without food restriction for 1 week. There were four replicates for each mice group (initial set, untreated, model, control, test) at each time point. In the first week, mice in the control group and the test group were daily administrated with bacteria (BL21: $p$ ETDuet1-O for the control group, BL21: $p E T$ Duet1-1 for the Test group. $\mathrm{OD}_{600}=1$ ) in a total volume of $0.3 \mathrm{~mL} 0.9 \% \mathrm{NS}$ suspension. Other three groups were daily administrated with the same volume of $0.9 \%$ NS. At the time point of $0 \mathrm{~h}$, mice of the initial set were killed to test colon $\mathrm{pH}$ values as a reference, and mice of other four groups were administrated with the lactose solution (12 mg of lactose per $20 \mathrm{~g}$ of body weight). In the following $6 \mathrm{~h}$, four mice of each group were killed at each time point $(1 \mathrm{~h}, 2 \mathrm{~h}, 3 \mathrm{~h}, 4 \mathrm{~h}, 6 \mathrm{~h})$ for $\mathrm{pH}$ measurements. The whole mice colon contents were removed and mixed, and the $\mathrm{pH}$ was determined using a precalibrated pH FE28-Meter (Mettler-Toledo). pH measurements were taken three times with the colon contents being re-mixed, the $\mathrm{pH}$ meter being washed with distilled water, and the calibration checked between measurements.

Another set of the four groups of mice was used to test fecal $\beta$-GAL activity, including (1) untreated group $(\mathrm{n}=3)$, (2) model group ( $\mathrm{n}=3)$, (3) control group ( $\mathrm{n}=$ $3)$, and (4) test group $(n=3)$. The operations in the first week and at the time point of $0 \mathrm{~h}$ were the same as the operations described above. The mice feces were collected by stimulated defecation. The collected feces were washed with the phosphate buffer saline (PBS) for three times and suspended with the PBS (mass of feces: volume of PBS = 1:9). The suspension liquid was then crushed with ultrasound and centrifuged at $5000 \times \mathrm{g}$ for $10 \mathrm{~min}$. The supernatant was taken for testing $\beta$-GAL activity, determined by the colour reaction of $\mathrm{p}$ nitrophenol using $\beta$-galactosidase $(\beta$-GAL) activity test kit (Solarbio, Cat. No. BC2585, Beijing, China).

\section{1-day in vivo model}

The 21-day in vivo model was conducted on postweaning BALB/c mice. Male BALB/c mice from animal care aged 7 8 weeks were used for the trial. Before the test, mice were housed under specific pathogen-free (SPF) conditions with a 12-h light/dark cycle (8 AM-8 PM for light, 8 PM-8 AM next day for dark) and a normal diet for 1 week. Ten replicates of each group (untreated, model, control, and test) were identified by pierced ear labels and separate cages (Additional file 1: Table S8). The trial was divided into the following 4 phases: Phase I: 3 days of normal conditions; phase II: 6 days of lactose challenge; Phase III: 6 days of bacterial treatment; and Phase IV: 6 days of restoration. The four groups of mice were treated differently during the four phases. Untreated group: normal care during four phases, with $0.9 \%$ saline gavage at Phase II and Phase III (the volume of saline was the same as the volume of lactose and bacteria solution used in the other groups). Model group: normal care at Phase I, followed by lactose solution gavage $(12 \mathrm{mg}$ of lactose per $20 \mathrm{~g}$ of body weight) during phases II and III, and $0.9 \%$ saline gavage with the same volume as that of the bacteria solution used in the other groups. Control group: normal care at Phase I, followed by lactose solution gavage $(12 \mathrm{mg}$ of lactose per $20 \mathrm{~g}$ of body weight) during phases II and III, and $0.3 \mathrm{~mL}$ of control bacteria solution gavage (BL21: pETDuet1-0, $\mathrm{OD}_{600}=1$ ) during Phase III. Test group: normal care at Phase I, followed by lactose solution gavage (12 mg of lactose per $20 \mathrm{~g}$ of body weight) during phases II and III, and $0.3 \mathrm{~mL}$ of engineered bacteria solution gavage (BL21: pETDuet1-0, $\mathrm{OD}_{600}=1$ ) during Phase III. All mice in the groups were raised under normal conditions during Phase IV. Three feces pellets were collected from each mouse at 2:00 PM each day.

\section{DNA extraction and 16S rRNA gene sequencing}

The total genomic DNA from the feces samples was extracted using a QIAamp ${ }^{\circ}$ Fast DNA Stool Mini Kit (QIAGEN) according to the manufacturer's protocol. 
The DNA concentration was determined with a Qubit3.0 Fluorometer. A 20-30 ng quantity of DNA was used to generate amplicons. The V3 and V4 regions were amplified using forward primers containing the sequence "CCTACGGRRBGCASCAGKVRVGAAT" and reverse primers containing the sequence "GGACTACNVGGGTWTCTAATCC." Simultaneously, indexed adapters were added to the ends of the $16 \mathrm{~S}$ rDNA amplicons to generate indexed libraries ready for downstream NGS sequencing on Illumina MiSeq. PCR reactions were performed in triplicate $25 \mu \mathrm{L}$ mixtures containing $2.5 \mu \mathrm{L}$ of TransStart Buffer, $2 \mu \mathrm{L}$ of dNTPs, $1 \mu \mathrm{L}$ of each primer, and $20 \mathrm{ng}$ of template DNA. The concentrations of the DNA libraries were validated by Qubit3.0 Fluorometer. After the DNA libraries were quantified at $10 \mathrm{nM}$, they were multiplexed and loaded on an Illumina MiSeq instrument according to the manufacturer's instructions. Sequencing was performed using a PE250/300 paired-end approach. The sequencing data are accessible in NCBI SRA (with project accession number SRP152069).

\section{Sequence analysis}

The raw multiplexed-paired-end sequences were firstly input to QIIME2 (version 2020.11.0) [36] and were demultiplexed using "qiime cutadapt demux-paired" with "--p-error-rate 0." The primers of demultiplexed sequences were then trimmed using "qiime cutadapt trimpaired" with "--p-match-adapter-wildcards --p-matchread-wildcards --p-discard-untrimmed." The trimmed sequences were quality-controlled using "qiime dada2 denoise-paired" with "--p-trunc-len-f 275 --p-trunc-len-r 220 --p-n-threads 20 --p-min-fold-parent-over-abundance 4." The dada2-produced feature table was rarefied to 4000 reads per sample using "qiime feature-table rarefy" with "--p-sampling-depth 4000" based on the curve plateaus of alpha diversity. The dada2-produced representative sequences were taxonomically annotated using "qiime feature-classifier classify-sklearn" against the V3V4 region of the Silva 138 database [37]. The taxonomic annotations were integrated into the rarefied feature table using "qiime taxa collapse."

\section{Jensen-Shannon divergence distance}

The Jensen-Shannon divergence (JSD) distance $D(a, b)$ between samples $a$ and $b$ is defined as

$$
D(a, b)=\sqrt{\operatorname{SSD}\left(p_{a}, p_{b}\right)}
$$

where $p_{a}$ and $p_{a}$ are the abundance distributions of samples $a$ and $b$ and $\operatorname{JSD}(x, y)$ is the JSD between two abundance distributions of genus $x$ and genus $y$ defined as

$$
J S D(x, y)=\frac{1}{2} K L D(x, m)+\frac{1}{2} K L D(y, m)
$$

where $m=\frac{x+y}{2}$ and $K L D(x, y)$ is the Kullback-Leibler divergence between $x$ and $y$ defined as

$$
K L D(x, y)=\sum_{i} x_{i} \log \frac{x_{i}}{y_{i}}
$$

We added a pseudocount of 0.000001 to the abundance distributions and renormalized them to avoid zero in the numerator and/or denominator of Eq. (3).

\section{Principal coordinate analysis}

R function "dudi.pco" in the R package "ade4" was used to perform principal coordinate analysis ( $\mathrm{PCoA})$ on the JSD distance matrix. R package "ggplot2" was finally used to visualize the results.

\section{Microbiota network construction}

Amplicon sequence variants (ASVs) with at least 20\% prevalence among all samples were used to construct microbiota network. The unweighted-glasso network was constructed using "spiec.easi" in R package "SpiecEasi" (version 1.1.0) [38], with "method = 'glasso', lambda.min.ratio $=0.01$, nlambda $=20$, pulsar.params $=$ list (rep.num $=50)$ ". Samples from the untreated group at days 7 and 11 were used to construct the network of "normal condition." Samples from the model and control at days 5,7 , and 11 , and test groups at days 5 and 7 were used for the network of "lactose feeding." Samples from the test group at days 11 and 13 were used for the network of "treatment."

\section{Statistical analysis}

For categorical metadata, samples were pooled into bins (Phase I/Phase II..., Day 3/Day 5/Day 7...) and significant features were identified using Mann-Whitney-Wilcoxon Test with Benjamini and Hochberg correction of $P$ values.

\section{Supplementary Information}

The online version contains supplementary material available at https://doi. org/10.1186/s12915-021-01070-9.

\footnotetext{
Additional file 1 Table S1 to S9. Detailed data of results. Table S1: Detailed sequences of all the parts of our designed circuits; Table S2: Raw data for the fluorescence measurement of the protein \& promoter; Table S3: Raw data for the fluorescence measurement of the protein \& protein interaction of CIII \& CII; Table S4: Parameters for tri-stable circuit modelling; Table S5: The variation of $\mathrm{pH}, \beta$-galactosidase activity and Ilactate dehydrogenase activity in in vitro experiment to confirm the functionality of the circuit; Table S6: The variation of $\mathrm{pH}$ of the mice colon in the in vivo experiment to confirm the functionality of the circuit; Table S7: The variation of the $\beta$-galactosidase of the mice feces in the in vivo experiment to confirm the functionality of the circuit. Table S8: The experiment design and fecal sample collection of the 21-days in vivo experiment to detect the variation of mice gut microbiota; Table S9: The
} 
mean abundance of ASVs in the network and their taxonomic annotations.

Additional file 2. Supplementary results. The supplementary results of fluorescence detection, testing colonisation of the bacteria, testing the cage effects on gut microbiota.

Additional file 3 The plasmid profile of pETDuet1-1.

Additional file 4 The plasmid profile of pETDuet1-0.

Additional file 5. Table S10 to S15. Detailed parameters of the methods. Table S10: Regular PCR reaction system; Table S11: Double enzyme reaction system; Table S12: Ligation system; Table S13: InFusion system; Table S14: Protocol for M9 minimal medium preparation; Table S15: Instrument setting of the plate reader for fluorescence measurement.

\section{Acknowledgements}

We thank all that have provided assistance for IGEM team HUST-China in iGEM 2016. We thank LetPub (www.letpub.com) for its linguistic assistance during the preparation of this manuscript.

\section{Authors' contributions}

MY. C., ZY. C., YJ. Y., Y. Z., and K. N. designed the experiments. JM. L. and YG. T. conducted the DNA extraction and sequencing. MY. C., ZY. C., YY. Y., WJ. L., ZY. G., JY. Q., Z. Z., L. D., YF. M., and RH. L. conducted the plasmid constructions, fluorescence detection, and data analysis. MY. C., ZY. C., YY. Y, CX. P., and YH. L. conducted the in vitro and in vivo experiments. MY. C. and ZY. C. produced the figures and wrote the manuscript. YJ. Y., Y. Z., and K. N. supervised the study, and reviewed and revised the manuscript. All authors read and approved the final manuscript.

\section{Funding}

This project was supported by grants from the Ministry of Science and Technology of People's Republic of China (Grant No. 2018YFC0910502), the National Natural Science Foundation of China (Grant No. NSFC32071465, NSFC-31871334 and NSFC-31671374), the Teaching Research Program from Hubei Province of China (Grant No. 2016071), and the National Undergraduate Training Programs for Innovation and Entrepreneurship (Grant No. 201710487069) from HUST and the Ministry of Education of China.

\section{Availability of data and materials}

The datasets generated and analyzed during the current study are available in the short read archive (SRA) section of National Center for Biotechnology Information, under accession SRP152069 [39].

\section{Declarations}

\section{Ethics approval and consent to participate}

Not applicable.

\section{Consent for publication}

Not applicable.

\section{Competing interests}

The authors declare that they have no competing interests.

\footnotetext{
Author details

${ }^{1}$ College of Life Science and Technology, Huazhong University of Science and Technology, 430074 Wuhan, People's Republic of China. ${ }^{2}$ Innovation Base of Life Science and Technology, Qiming College, Huazhong University of Science and Technology, 430074 Wuhan, People's Republic of China. ${ }^{3}$ Key Laboratory of Molecular Biophysics of the Ministry of Education, Huazhong University of Science and Technology, 430074 Wuhan, People's Republic of China. ${ }^{4}$ State Key Laboratory of Pathogen and Biosecurity, Beijing Institute of Microbiology and Epidemiology, 100071 Beijing, People's Republic of China. ${ }^{5}$ Beijing Advanced Innovation Center for Soft Matter Science and Engineering (BAIC-SM), College of Life Science and Technology, Beijing University of Chemical Technology, Beijing, 100029 Beijing, People's Republic of China.
}

Received: 13 September 2020 Accepted: 9 June 2021

Published online: 05 July 2021

\section{References}

1. Storhaug CL, Fosse SK, Fadnes LT. Country, regional, and global estimates for lactose malabsorption in adults: a systematic review and meta-analysis. Lancet Gastroenterol Hepatol. 2017;2(10):738-46. https://doi.org/10.1016/S24 68-1253(17)30154-1.

2. Fassio F, Facioni MS, Guagnini F. Lactose maldigestion, malabsorption, and intolerance: a comprehensive review with a focus on current management and future perspectives. Nutrients. 2018;10(11). https://doi.org/10.3390/nu1 0111599.

3. de Vrese M, Stegelmann A, Richter B, Fenselau S, Laue C, Schrezenmeir J. Probiotics--compensation for lactase insufficiency. Am J Clin Nutr. 2001;73: $421 \mathrm{~s}-9 \mathrm{~s}$.

4. Heyman M. Effect of lactic acid bacteria on diarrheal diseases. J Am Coll Nutr. 2000;19:137s-46s.

5. Bohmer CJ, Tuynman HA. The effect of a lactose-restricted diet in patients with a positive lactose tolerance test, earlier diagnosed as irritable bowel syndrome: a 5-year follow-up study. Eur J Gastroenterol Hepatol. 2001;13(8): 941-4. https://doi.org/10.1097/00042737-200108000-00011.

6. Shaukat A, Levitt MD, Taylor BC, MacDonald R, Shamliyan TA, Kane RL, et al. Systematic review: effective management strategies for lactose intolerance. Ann Intern Med. 2010;152(12):797-803. https://doi.org/10.7326/0003-4819-1 52-12-201006150-00241.

7. Wilder-Smith CH, Olesen SS, Materna A, Drewes AM. Predictors of response to a low-fodmap diet in patients with functional gastrointestinal disorders and lactose or fructose intolerance. Aliment Pharmacol Ther. 2017:45(8): 1094-106. https://doi.org/10.1111/apt.13978.

8. Azcarate-Peril MA, Ritter AJ, Savaiano D, Monteagudo-Mera A, Anderson C, Magness ST, et al. Impact of short-chain galactooligosaccharides on the gut microbiome of lactose-intolerant individuals. Proc Natl Acad Sci U S A. 2017; 114(3):E367-e75. https://doi.org/10.1073/pnas.1606722113.

9. Ianiro G, Pecere S, Giorgio V, Gasbarrini A, Cammarota G. Digestive enzyme supplementation in gastrointestinal diseases. Curr Drug Metab. 2016;17(2): 187-93. https://doi.org/10.2174/138920021702160114150137.

10. Ojetti V, Gigante G, Gabrielli M, Ainora ME, Mannocci A, Lauritano EC, et al. The effect of oral supplementation with lactobacillus reuteri or tilactase in lactose intolerant patients: Randomized trial. Eur Rev Med Pharmacol Sci. 2010;14(3):163-70.

11. Almeida CC, Lorena SL, Pavan CR, Akasaka HM, Mesquita MA. Beneficial effects of long-term consumption of a probiotic combination of lactobacillus casei shirota and bifidobacterium breve yakult may persist after suspension of therapy in lactose-intolerant patients. Nutr Clin Pract. 2012; 27(2):247-51. https://doi.org/10.1177/0884533612440289.

12. He T, Priebe MG, Zhong Y, Huang C, Harmsen HJ, Raangs GC, et al. Effects of yogurt and bifidobacteria supplementation on the colonic microbiota in lactose-intolerant subjects. J Appl Microbiol. 2008;104(2):595-604. https:// doi.org/10.1111/j.1365-2672.2007.03579.x.

13. Oak SJ, Jha R. The effects of probiotics in lactose intolerance: a systematic review. Crit Rev Food Sci Nutr. 2019;59(11):1675-83. https://doi.org/10.1 080/10408398.2018.1425977.

14. Tomizawa M, Tsumaki K, Sone M. Characterization of the activity of betagalactosidase from Escherichia coli and drosophila melanogaster in fixed and non-fixed drosophila tissues. Biochim Open. 2016;3:1-7. https://doi. org/10.1016/j.biopen.2016.06.001.

15. Juajun $\mathrm{O}$, Nguyen $\mathrm{TH}$, Maischberger $\mathrm{T}$, lqbal $\mathrm{S}$, Haltrich $\mathrm{D}$, Yamabhai $\mathrm{M}$. Cloning, purification, and characterization of beta-galactosidase from bacillus licheniformis dsm 13. Appl Microbiol Biotechnol. 2011;89(3):645-54. https://doi.org/10.1007/s00253-010-2862-2.

16. Hilton IB, Gersbach CA. Enabling functional genomics with genome engineering. Genome Res. 2015;25(10):1442-55. https://doi.org/10.1101/gr.1 90124.115.

17. Saeidi N, Wong CK, Lo TM, Nguyen HX, Ling H, Leong SS, et al. Engineering microbes to sense and eradicate pseudomonas aeruginosa, a human pathogen. Mol Syst Biol. 2011;7(1):521. https://doi.org/10.1038/msb.2011.55.

18. Danino T, Prindle A, Kwong GA, Skalak M, Li H, Allen K, et al. Programmable probiotics for detection of cancer in urine. Sci Transl Med. 2015;7:289ra84.

19. Hwang IY, Koh E, Wong A, March JC, Bentley WE, Lee YS, et al. Engineered probiotic Escherichia coli can eliminate and prevent pseudomonas 
aeruginosa gut infection in animal models. Nat Commun. 2017;8(1):15028. https://doi.org/10.1038/ncomms15028.

20. Li J, Zhang W, Wang C, Yu Q, Dai R, Pei X. Lactococcus lactis expressing food-grade beta-galactosidase alleviates lactose intolerance symptoms in post-weaning balb/c mice. Appl Microbiol Biotechnol. 2012;96(6):1499-506. https://doi.org/10.1007/s00253-012-3977-4.

21. Zhang W, Wang C, Huang C, Yu Q, Liu H, Zhang C, et al. Construction and expression of food-grade beta-galactosidase gene in lactococcus lactis. Curr Microbiol. 2011;62(2):639-44. https://doi.org/10.1007/s00284-010-9756-5.

22. Rajkumar AS, Liu G, Bergenholm D, Arsovska D, Kristensen M, Nielsen J, et al. Engineering of synthetic, stress-responsive yeast promoters. Nucleic Acids Res. 2016;44(17):e136. https://doi.org/10.1093/nar/gkw553.

23. Ptashne M. A genetic switch: gene control and phage. Lambda. 1986.

24. Evans DF, Pye G, Bramley R, Clark AG, Dyson TJ, Hardcastle JD. Measurement of gastrointestinal ph profiles in normal ambulant human subjects. Gut. 1988;29(8):1035-41. https://doi.org/10.1136/gut.29.8.1035.

25. Schubert RA, Dodd IB, Egan JB, Shearwin KE. Cro's role in the Ci Cro bistable switch is critical for \{lambda\}'s transition from lysogeny to lytic development. Genes Dev. 2007;21 (19):2461-72. https://doi.org/10.1101/gad.1584907.

26. Halder $S$, Datta AB, Parrack P. Probing the antiprotease activity of lambda CIII, an inhibitor of the Escherichia coli metalloprotease hflb (ftsh). J Bacteriol. 2007;189(22):8130-8. https://doi.org/10.1128/JB.00820-07.

27. Pocanschi $\mathrm{CL}$, Popot $\mathrm{L}$, Kleinschmidt JH. Folding and stability of outer membrane protein a (ompa) from Escherichia coli in an amphipathic polymer, amphipol a8-35. Eur Biophys J. 2013;42(2-3):103-18. https://doi. org/10.1007/s00249-013-0887-z.

28. Futai M, Kimura H. Inducible membrane-bound I-lactate dehydrogenase from Escherichia coli. Purification and properties. J Biol Chem. 1977;252(16):5820-7.

29. Kimura H, Futai M. Effects of phospholipids on H-lactate dehydrogenase from membranes of escherichia coli. Activation and stabilization of the enzyme with phospholipids. J Biol Chem. 1978;253(4):1095-110. https://doi.org/10.1 016/50021-9258(17)38116-4.

30. Herzig S, Raemy E, Montessuit S, Veuthey JL, Zamboni N, Westermann B, et al. Identification and functional expression of the mitochondrial pyruvate carrier. Science. 2012;337(6090):93-6. https://doi.org/10.1126/science.1218530.

31. Kristoficova I, Vilhena C, Behr S, Jung K. Btst, a novel and specific pyruvate/ h(+) symporter in Escherichia coli. J Bacteriol. 2018;200(2). https://doi.org/1 0.1128/JB.00599-17.

32. Deng Y, Ma N, Zhu K, Mao Y, Wei X, Zhao Y. Balancing the carbon fluX distributions between the TCA cycle and glyoxylate shunt to produce glycolate at high yield and titer in escherichia coli. Metab Eng. 2018;46:28-34. https:/doi.org/10.1016/j.ymben.2018.02.008.

33. McConnell EL, Basit AW, Murdan S. Measurements of rat and mouse gastrointestinal $\mathrm{pH}$, fluid and lymphoid tissue, and implications for in-vivo experiments. J Pharm Pharmacol. 2008;60(1):63-70. https://doi.org/10.1211/ jpp.60.1.0008.

34. Yang JY, Lee YS, Kim Y, Lee SH, Ryu S, Fukuda S, et al. Gut commensal Bacteroides acidifaciens prevents obesity and improves insulin sensitivity in mice. Mucosal Immunol. 2017;10(1):104-16. https://doi.org/10.1038/mi.2016.42.

35. Je S, Fritsch E, Maniatis T. Molecular cloning: a laboratory manual. 1983;33.

36. Bolyen E, Rideout JR, Dillon MR, Bokulich NA, Abnet CC, Al-Ghalith GA, et al. Reproducible, interactive, scalable and extensible microbiome data science using qiime 2. Nat Biotechnol. 2019;37(8):852-7. https://doi.org/10.1038/s41 587-019-0209-9.

37. Quast C, Pruesse E, Yilmaz P, Gerken J, Schweer T, Yarza P, et al. The silva ribosomal RNA gene database project: improved data processing and webbased tools. Nucleic Acids Res. 2013;41(Database issue):D590-6. https://doi. org/10.1093/nar/gks1219.

38. Kurtz ZD, Müller CL, Miraldi ER, Littman DR, Blaser MJ, Bonneau RA. Sparse and compositionally robust inference of microbial ecological networks. PLoS Comput Biol. 2015;11(5):e1004226. https://doi.org/10.1371/journal.pcbi.1 004226

39. Cheng M, Cheng Z, Yu Y, Liu W, Li R, Guo Z, et al. Gut microbial variation in lactose intolerance mice with intervention of synthetic bacteria. SRA https://identifiers.org/insdc.sra:SRX4399439. 2018.

\section{Publisher's Note}

Springer Nature remains neutral with regard to jurisdictional claims in published maps and institutional affiliations.

\section{Ready to submit your research? Choose BMC and benefit from}

- fast, convenient online submission

- thorough peer review by experienced researchers in your field

- rapid publication on acceptance

- support for research data, including large and complex data types

- gold Open Access which fosters wider collaboration and increased citations

- maximum visibility for your research: over $100 \mathrm{M}$ website views per year

At BMC, research is always in progress.

Learn more biomedcentral.com/submissions 